Article

\title{
Synchrotron-Based HR-Fluorescence and Mineralogical Mapping of the Initial Growth Stages of Polynesian Cultivated Pearls Disprove the 'Reversed Shell' Concept
}

\author{
Jean-Pierre Cuif ${ }^{1, *(\mathbb{D})}$, Yannicke Dauphin ${ }^{2,3}{ }^{\mathbb{D}}$, Cédrik Lo ${ }^{4}$, Kadda Medjoubi ${ }^{5}$, Denis Saulnier 6 \\ and Andrea Somogyi 5
}

check for

updates

Citation: Cuif, J.-P.; Dauphin, Y.; Lo,

C.; Medjoubi, K.; Saulnier, D.;

Somogyi, A. Synchrotron-Based HR-Fluorescence and Mineralogical Mapping of the Initial Growth Stages of Polynesian Cultivated Pearls

Disprove the 'Reversed Shell'

Concept. Minerals 2022, 12, 172.

https://doi.org/10.3390/

$\min 12020172$

Academic Editor: Denis Gebauer

Received: 6 December 2021

Accepted: 26 January 2022

Published: 29 January 2022

Publisher's Note: MDPI stays neutral with regard to jurisdictional claims in published maps and institutional affiliations.

Copyright: (C) 2022 by the authors. Licensee MDPI, Basel, Switzerland. This article is an open access article distributed under the terms and conditions of the Creative Commons Attribution (CC BY) license (https:// creativecommons.org/licenses/by/ $4.0 /)$
1 Centre de Recherche sur la Paléodiversité et les Paléoenvironnements (CR2P), UMR 7207, Muséum National d'Histoire Naturelle CNRS, Sorbonne Université, 75005 Paris, France

2 Institut de Systématique, Evolution, Biodiversité (ISYEB), UMR 7205 CNRS MNHN Sorbonne-Université, EPHE, Muséum National d'Histoire Naturelle, 75005 Paris, France; yannicke.dauphin@upmc.fr

3 Department of Biomaterials, Max-Planck Institute of Colloids and Interfaces, 14476 Potsdam, Germany

4 Direction des Ressources Marines, BP 20, 98713 Papeete, French Polynesia; cedrik.lo@drm.gov.pf

5 Synchrotron Soleil, 91190 Saint Aubin, France; kadda.medjoubi@synchrotron-soleil.fr (K.M.); andrea.somogyi@synchrotron-soleil.fr (A.S.)

6 Ifremer, UMR 241 Environnement Insulaire Océanien (EIO), Labex Corail, Centre du Pacifique, BP 49, 98719 Vairao, French Polynesia; denis.saulnier@ifremer.fr

* Correspondence: jean-pierre.cuif@orange.fr or jean-pierre.cuif@mnhn.fr

\begin{abstract}
In a series of Polynesian pearls collected after short cultivation periods, early post-grafting mineral deposits were characterized by high resolution synchrotron-based X-ray fluorescence with unprecedented accuracy. Morphological patterns and elemental composition are correlated through simultaneous imaging processes. Evidence that aragonite and calcite occur in neighboring units during the earliest biomineralization stages reveals that the grafting process can result in a greater degradation than usually admitted in the widely shared 'reversed shell' concept. Compared with ultrastructure of the pristine nacreous tablets, this method enables a precise evaluation of the possible biological changes in the biomineralization mechanism during grafting.
\end{abstract}

Keywords: pearl development; biocrystallization; X-ray fluorescence; mineralogy

\section{Introduction}

Commercialization of cultivated pearls started more than a century ago, and during this period a remarkable event occurred in 1924. After the success of the Mikimoto's promotional journey in America and Europe, the Paris trial was initiated to formally establish the status of the cultivated pearls. Officially commissioned experts were asked to compare the fine structure of the nacre produced by naturally grown pearls and those from the cultivated pearls then exclusively produced in Japan.

Examination by using optical microscopy was the only available method, and after careful investigations, nacre of the cultivated pearls was declared equivalent to the nacre of the naturally grown ones. This conclusion resulted in the still valid commercial compromise: both natural and cultivated products can be named 'pearls', but only the naturally grown ones deserve to be named 'natural pearls'. This conclusion also supported the common opinion that in the 'host' animal, the grafts (and later the 'pearl sacs': see Supplementary File S1) continue the nacreous mineralizing activity previously running in the 'donor' animal. To summarize, nacre was admittedly deposited onto the spherical surface of a nucleus by the metabolic process running for nacre production in the shell and natural pearls.

Contrasting with this common opinion, Kawakami's observations [1,2] made it obvious that after complete wrapping of the nucleus by the graft, the resulting newly established 
pearl sac can produce calcite. Therefore, between their initial secretion activity as a part of the nacre producing area in the 'donor' oyster, and their mineralizing activity in the grafted pearl oyster, the mineralizing cells of the pearl sac have undergone metabolic changes.

Taking into account that the Pinctada shells are built by two main mineral layers from which the external one is calcite $[3,4]$, Kawakami suggested that after grafting operation the pearl sac was starting a 'regeneration' process comparable to shell development. Through a series of converging studies [5-7], this hypothesis was so widely accepted that it is now integrated in the current model of biomineralization for cultivated pearls, leading to the concept of pearls viewed as 'reversed shells' [8]. To summarize, the first organic deposition onto a nucleus surface of a pearl is assimilated to the shell's periostracum, the calcite units of the pearls admittedly reproduce the prismatic layer of the pearl oyster, whereas nacre of the pearls is considered equivalent to nacre of the shell. As a result, the nacreous layer, the more internal component of a pearl oyster shell, becomes the more external component of the pearls (Supplementary File S1).

Such an alteration of the mineralizing process in the cultivated pearls has long remained underestimated because, in the pearl producing sites, it is visible after a two year growth period, wherein most pearls exhibit an outer surface covered by nacre. The only intriguing point was (and still is) that a significant proportion of the harvested pearls are no longer spherical but morphologically irregular.

Various characterizations of the pearl layer of cultivated pearls suggested that such postulated equivalences between the structures of shells and the hypothesized pearl growth steps do not fully reflect the biological processes of pearl development [9-12]. Not only can calcite occur, but the metabolic disturbances appeared even stronger than admitted: aragonite and calcite can be simultaneously produced within radially oriented envelopes (perpendicular to nucleus surface), a pattern that never occurs in shell microstructures. Moreover, mineralization patterns in the early pearl layers can differ not only between pearls, but within a given specimen (Figure 1).

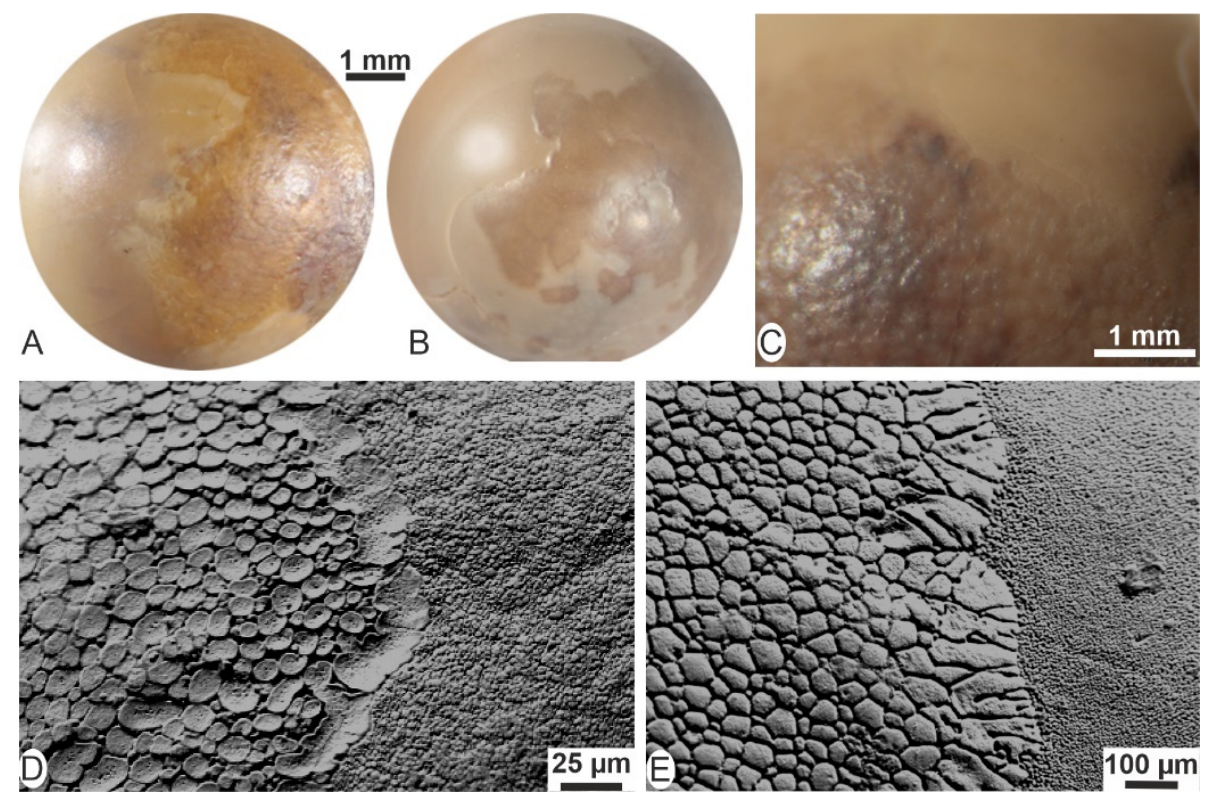

Figure 1. Morphology of the first pearl layer deposits onto nucleus surface. (A,B) Optical view of the outer surface showing heterogeneity of the mineral deposits and difference between the two samples. (C) Detail showing the irregular surface of 30-day post-grafting pearl layer. (D,E) SEM images of the surfaces of the early pearl layer evidencing heterogeneity of the mineral depositions.

Now, high-resolution synchrotron-based methods enable exploration of these unexpectedly complex mineral structures with unprecedented accuracy. Here we report how 
structural and compositional properties of the earliest materials deposited by the pearl sac lead to in-depth re-examination of the overall interpretation of pearl formation.

\section{Material and Methods}

\subsection{Materials}

Specimens were obtained from Polynesian pearls produced during experimental programs dealing with Pinctada margaritifera (the 'black lipped' pearl oyster). The extensive ADEQUA collaborative program involved the Direction des Resources Marines of Polynesia (DRM, Papeete) and the IFREMER biological station at Vairao. A more focalized experiment carried out by the IFREMER biological station involving two series of pearls grown at Rangiroa and Vairao (Tahiti) were collected after growth periods ranging from 10 days to 30 days.

Pearl sac tissues, and the underlying nucleus bearing the newly deposited minerals, were separately preserved. Contact between water and the freshly deposited mineral substances was avoided to prevent any dissolution/recrystallization process (individual envelopes covered by a paraffin coating).

\subsection{Methods}

\subsubsection{Optical Microscopy}

Optical microscopy includes examination in transmission mode (using both polarized and non-polarized light) of fragments collected from the surface of the nucleus. An Axio Imager D2m (Zeiss, Iena, Germany) was used with the Archimed software (V5.4.1 Microvision). A ZEISS Standard Universal microscope (Iena, Germany) was used in ultraviolet (UV) epifluorescence mode using a mercury lamp fitted with a UV (365 nm) filter and fluorine objectives.

\subsubsection{Scanning Electron Microscopy}

Uncoated samples were examined using an FEI QUANTA FEG 600 in low vacuum and back scattered electron (BSE) and secondary electron (SE) modes (Max Planck Institute of Colloids and Interfaces, Potsdam, Germany). BSE consists of high-energy electrons reflected or back-scattered out of the specimen. As a result, mineral-enriched zones are brighter than those enriched in organic components. Then, selected samples were gold coated and observed in secondary electron mode (SE) using a JEOL JCM 6000 (Museum National d'Histoire Naturelle, Paris, France) and a Zeiss Gemini LEO 1550 (Max Planck Institute of Colloids and Interfaces, Potsdam, Germany) in secondary electron mode.

\subsubsection{X-ray Fluorescence (XRF) Nano-Imaging at the Nanoscopium Beamline} (Soleil Synchrotron)

The incident $\mathrm{X}$-ray beam of $17 \mathrm{keV}$ energy was focussed by a Kirkpatrick-Baez mirror at the sample position. The size of the focused beam was tailored between $60 \times 70 \mathrm{~nm}^{2}$ and $300 \times 300 \mathrm{~nm}^{2}$ to the desired spatial resolution. The elemental distribution maps were collected in continuous scanning (FLYSCAN) mode by two Si-drift detectors [13,14].

\subsubsection{X-ray Diffraction at the Nanoscopium Beamline (Soleil Synchrotron)}

Two-dimensional diffraction patterns were recorded by using a 2D detector with $512 \times 1024$ pixels and with a pixel size of $75 \mu \mathrm{m}$. The detector was placed at $4.5 \mathrm{~cm}$ from the sample $[13,14]$.

\subsubsection{Fourier Transform Infrared Spectrometry (FTIR)}

FTIR was performed using a Globar source and a Continuum IR microscope coupled to a Nexus FTIR bench (Thermo Nicolet) at CRCC (Museum National d'Histoire Naturelle, Paris, France). Spectra were collected in reflection mode with a resolution of $8 \mathrm{~cm}^{-1}$ and an aperture of $75 \times 75 \mu \mathrm{m}^{2}$. For each spectrum, 200 scans were accumulated in the wave 
number range $4000-700 \mathrm{~cm}^{-1}$. Analyses were carried out in situ on the outer surface of the pearl layer deposits.

\subsubsection{Micro-XANES (X-ray Absorption near Edge Structure) Spectroscopy Analyses}

Measurements were carried out at the ID21 X-ray micro-spectroscopy beamline of the European Synchrotron Radiation Facility (Grenoble, France) using the scanning X-ray microscope. An energy-dispersive silicon drift diode (Bruker, Berlin, Germany) with a collimated active area of $80 \mathrm{~mm}^{2}$ and equipped with a thin polymer window was used to collect the X-ray fluorescence (XRF) photons. The XANES energy scan at the S K-edge $(2472 \mathrm{eV})$ was achieved using a fixed-exit double-crystal Si(111) monochromator (Kohzu, Japan) located upstream the microscope. XANES spectra were acquired between $2.45 \mathrm{keV}$ and $2.53 \mathrm{keV}$. This experiment required the X-ray microscope to be operated under vacuum to avoid the strong absorption of the sulfur emission lines by air.

\section{Results}

3.1. Morphology of the Earliest Mineralized Units Established by X-ray Fluorescence and Crystallization Patterns Observed Using Polarized-Light Microscopy

The earliest minerals appear as isolated spots dispersed upon a non-mineralized substrate (Figure 2A). Observed by X-ray Ca fluorescence mapping, these spots appear morphologically different, but they are all built by distinct elements radiating from central points (Figure 2B). Closer examination of these units by polarization microscopy (Figure 2C,D) reveals the correspondence between calcium fluorescing areas and crystallized organization of their mineral components.

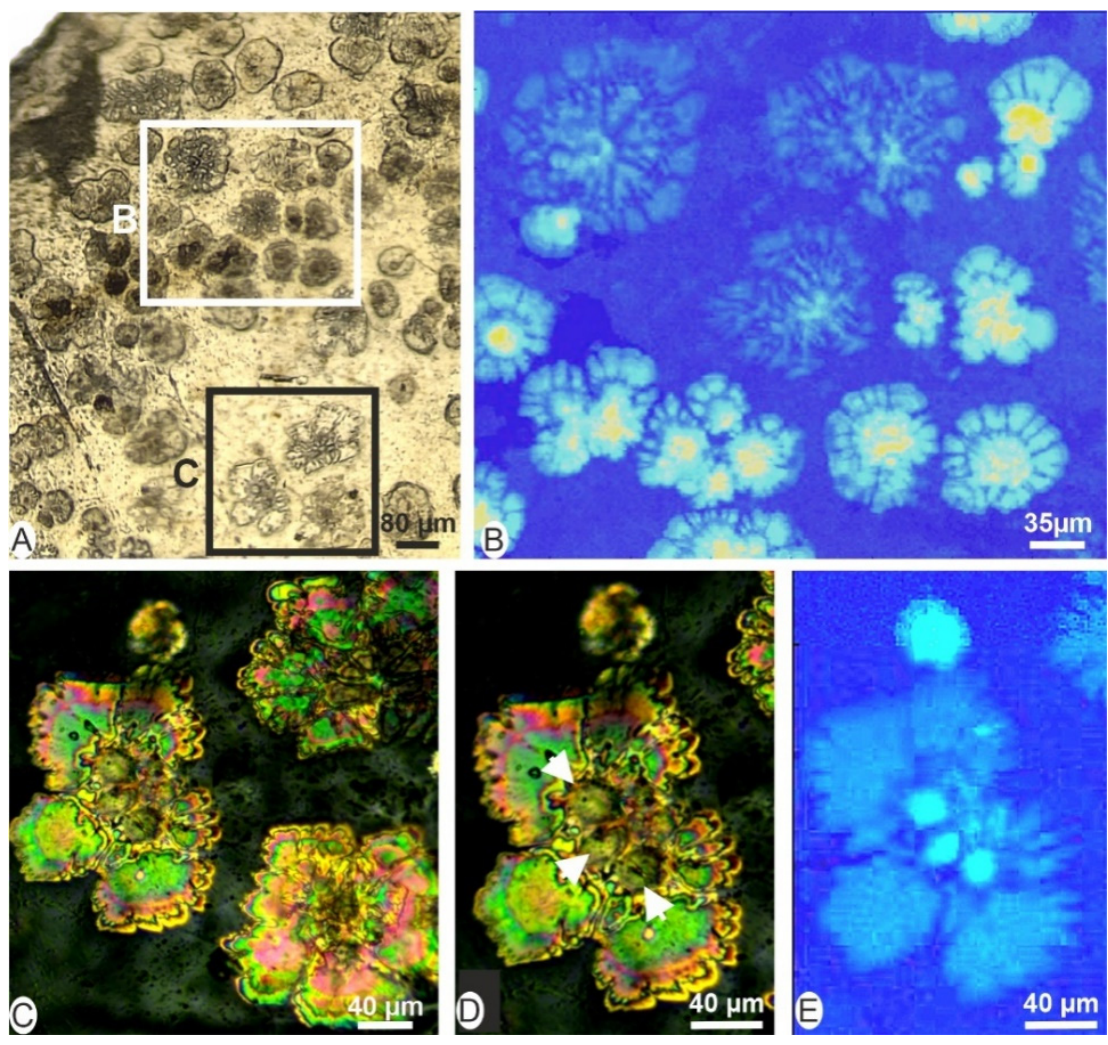

Figure 2. Example of initial mineralizations by the pearl sac; (A) Overall view of the detached fragment. (B) Morphological diversity of the minerals viewed by calcium fluorescence. (C,D) Polarized light microscopy of the minerals from area $C$ in (A). Note the similarity in marginal growth. (E) Calcium fluorescence of unit shown in (D). 


\subsection{Simultaneous Deposition of Calcite and Aragonite in Neighboring Units}

Fragment 2A also provides evidence of a simultaneous deposition of calcite and aragonite in close neighboring areas at the very beginning of the post-grafting mineralization process. Taking into account the mineral units of sector Figure 2A, area $\mathrm{C}$ extended to the neighboring unit (unit 4, Figure 3A), submitted to the $X$-ray beam, the four mineral units exhibit a similar response for calcium fluorescence (Figure 3B). However, submitted to $\mathrm{X}$-ray wavelength for strontium fluorescence, only unit 4 reveals a positive $\mathrm{Sr}$ concentration.

Moreover, the X-ray fluorescence mapping provides a framework for mineralogical characterization. Precisely localized X-ray diffraction measurements can be carried out by selecting any area of the illustrated sector, from a single pixel to any region of interest. Diffraction spectra were collected in the selected sectors of Figure 3D,E, resulting in the Figure $3 \mathrm{~F}, \mathrm{G}$ diagrams for calcite and aragonite respectively.

This method provides a double characterization of the earliest minerals undoubtedly establishing that at a distance of few tens of micrometers the pearl sac cells have created calcite and aragonite structures.
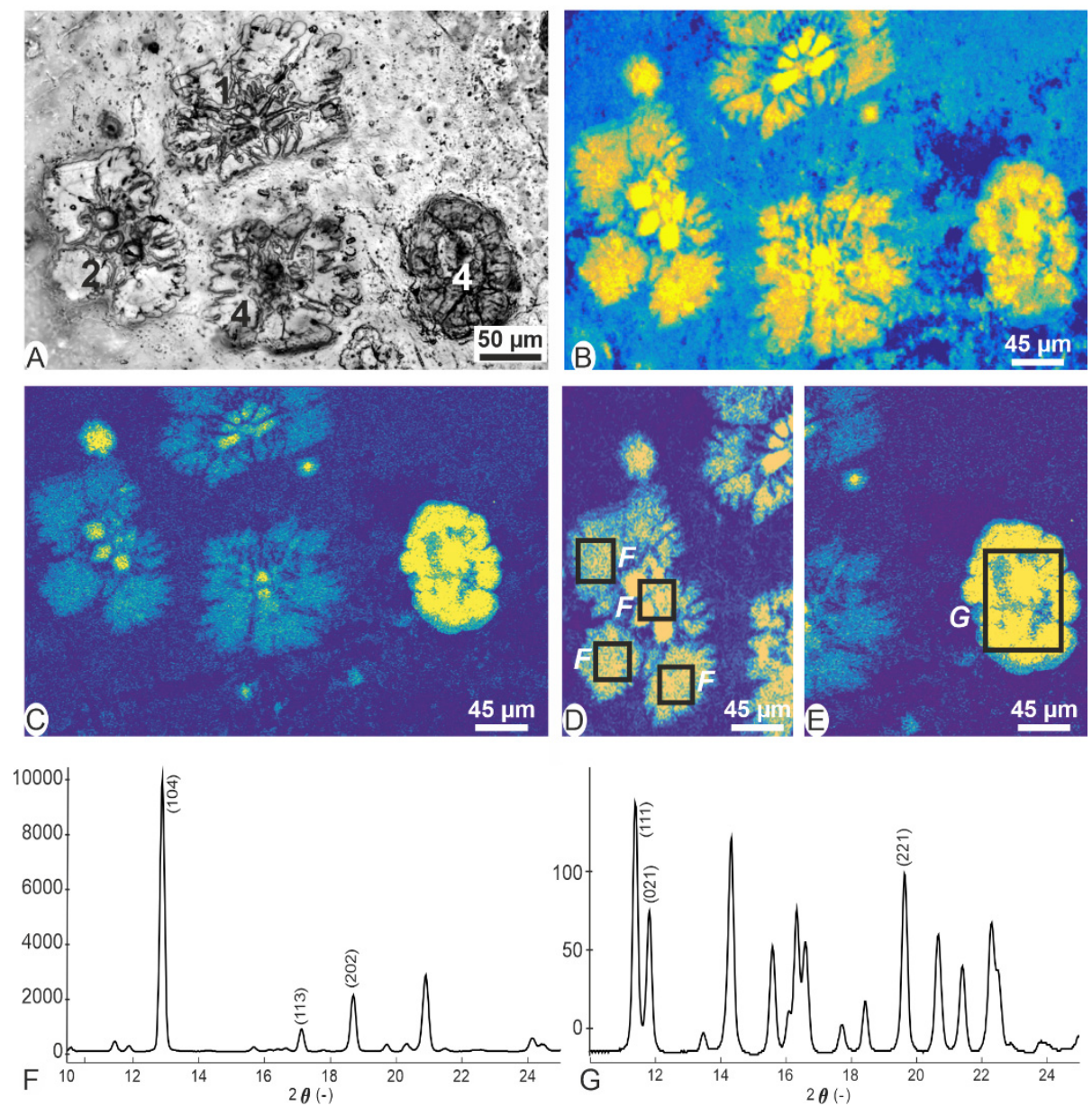

Figure 3. Simultaneous deposition of calcite and aragonite units in the first post-grafting mineralization stage. (A) Light microscope view (natural light) of four mineralized units. (B) Calcium fluorescence. (C) High strontium fluorescence in unit 4; low strontium fluorescence in units 1, 2, and 3. $(\mathbf{D}, \mathbf{E})$ Selected areas from which X-ray diffraction data were collected. $(\mathbf{F}, \mathbf{G})$ Corresponding X-ray diffraction diagrams. In both cases, typical diagrams for calcite $(\mathbf{F})$ and aragonite $(\mathbf{G})$ are obtained suggesting remarkable consistency in the orientation of the mineral particles.

\subsection{Differences in Physical Status for Calcite and Aragonite}

Applying the double characterization method to another sample (Figure 4A,B), the central unit and its close neighboring ones reveal that not only are the lateral and central 
units mineralogically different (calcite and aragonite respectively), but their physical status also appears remarkably distinct. These two distinct diffraction patterns indicate that in the sample areas submitted to incident X-ray beam (Figure 4C,D), calcite crystals are rather well developed leading to distinct diffraction spots, whereas aragonite is made of randomly oriented microcrystalline units (Figure 4E,F).
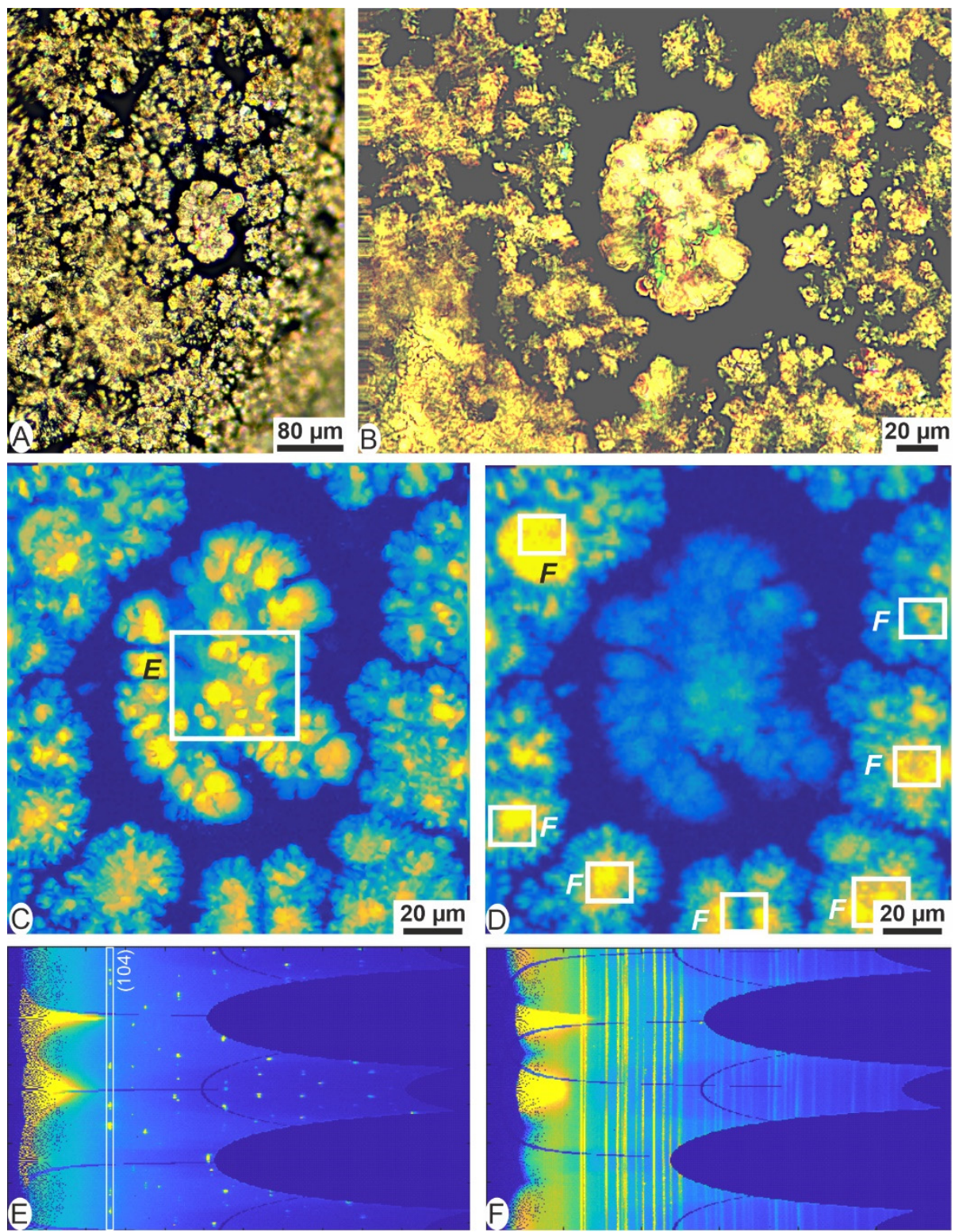

Figure 4. Mineralizing spots in which the distinct physical status of calcite and aragonite are established. (A,B) Natural view of the area. (C,D) High-resolution X-ray fluorescence for calcium (C) and strontium (D). (E,F) Diffraction diagrams for the central (E) and lateral (F) areas. Well crystallized calcite $((\mathbf{E})$ : distinct diffraction spots) and powder aragonite $((\mathbf{F})$ : small spots in continuous lines) are characterized in neighbor areas produced by the same pearl sac.

\subsection{Last Step in Coverage of the Nucleus: Branching Structure of the Convergent Mineralizing Units}

It is worth reminding that the final step in the grafting process was the insertion of an approximately $3 \mathrm{~mm} \times 3 \mathrm{~mm}$ fragment of living tissue onto the nucleus surface (Supplementary File S1). As nucleus is about 6 to $8 \mathrm{~mm}$ in diameter, the nucleus wrapping by the graft requests an initial expanding phase for the mineralizing cells, the end of which is reached when distinct units are in close contact: Figure 5A,B show such a status. 
Calcium and strontium fluorescence (Figure 5C,D respectively) shows the presence of aragonite (high Sr content on Figure 5D) among calcite irregular units. Closer mapping of the central area reveals that up to the last step of an expansion phase, the mineralizing mechanism does not produce compact crystals. On the opposite, a branching mineral structure is clearly illustrated by the HR-X-ray fluorescence mapping (Figure 5C,D). Polarized light microscope shows that the neighboring units exhibit distinct polarization patterns for these branching mineral areas (Figure 5E-G).
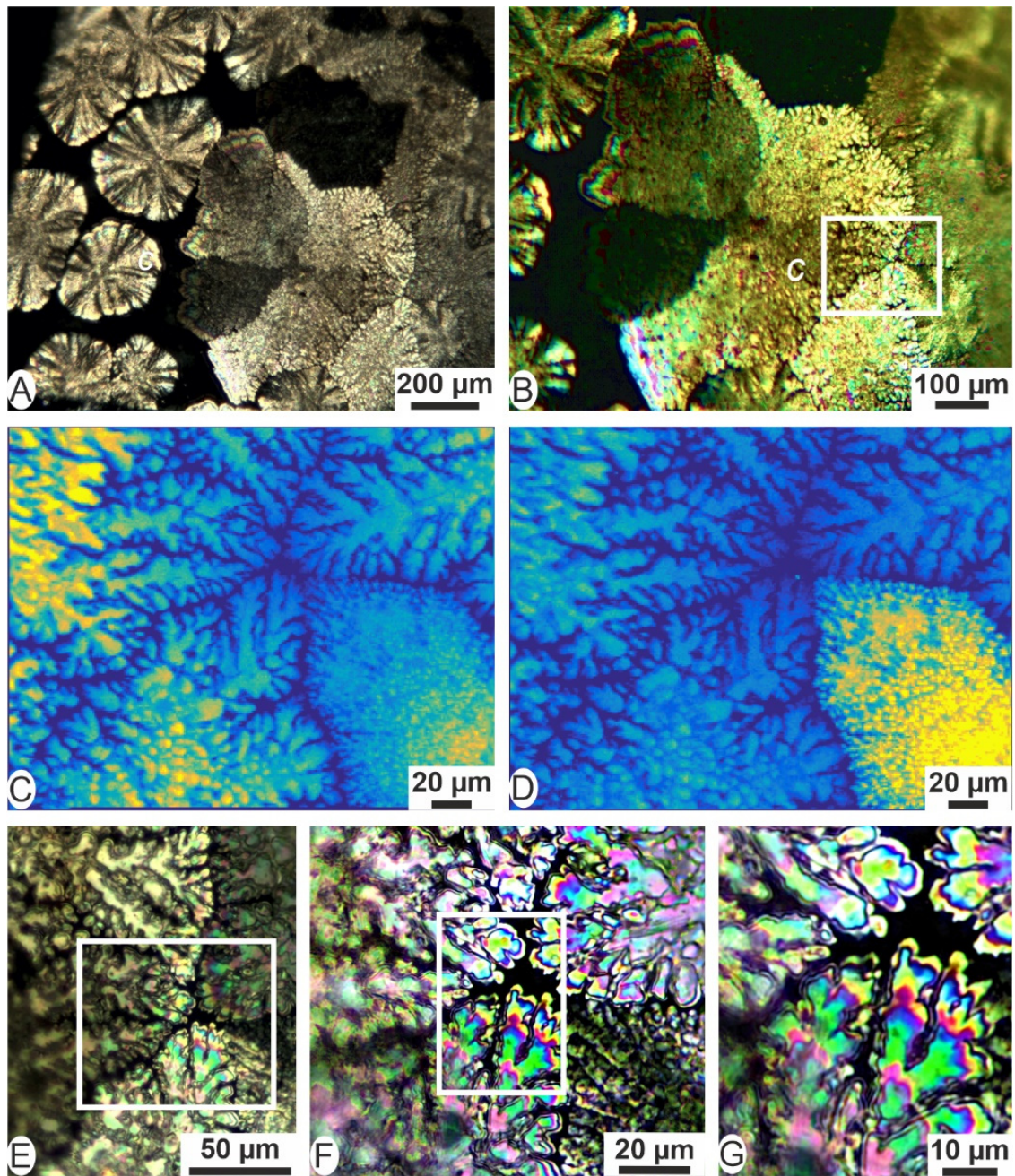

Figure 5. Structure of the mineralized units at the end of the graft expansion phase. (A,B) Each mineral unit viewed by optical microscopy (polarized light) exhibits distinct morphological and polarization patterns. (C,D) $\mathrm{Ca}(\mathbf{C})$ and $\mathrm{Sr}$ (D) HR-X-ray fluorescence of the selected area of Figure 2B (area C). (E-G) Polarization microscope view of the central part of the selected area; structures revealed by $\mathrm{X}$-ray fluorescence are built by a branching crystallized material.

\section{Discussion}

Kawakami suggested a 'regeneration process' when he discovered calcite in pearl layers [1,2]. The reversed shell theory considers that the mineralization sequence of a pearl layer first includes an organic layer assimilated to the shell periostracum, followed by calcite prisms and finally by nacre. This view explains both the inner position of the calcite structures in pearl layers and the regular presence of nacre at its outer surface (Supplementary File S1). Comparison between this scheme and the physical characterizations of the earliest post-grafting minerals leads to a different interpretation.

Previous investigations have shown that the calcite structures in the cultivated pearls exhibit distinct features from the scheme supporting the reversed shell theory. For instance, 
very important is the Figure 7 in [15], showing that uncontrolled morphology of the calcite units and prismatic calcite in the outer shell layer differ.

Focusing on the periostracum and its role in shell formation leads to an accentuated contrast with what occurs in the earliest post-grafting structures in pearls.

\subsection{Periostracum in the Pinctada Shells: Its Role in Shell Formation Compared with the Earliest Mineral Depositions in Pearls}

The crucial function of the periostracum in shell formation has been illustrated $[16,17]$ and summarized in Figure 6. Beginning in the deeper part of the outer mantle grove (Figure 6A), the thin rhythmically produced organic membrane not only ensures isolation of the mineralizing area from sea water, but actively participates in shell construction.

This role begins with deposition onto the internal side of the periostracum of regularly spaced spots of organic compounds, acting as centers of calcification (Figure 6A,B). During the upward transit of the periostracum to the shell growing edge (Figure 6A: blue arrow), these centers are repeatedly surrounded by concentric depositions of calcite resulting in globally circular units whose diameters grow up to cover almost the internal surface of the periostracum (Figure 6B-D). This is the 'flexible shell' built by distinct free growing calcite units. In spite of a mixed organo-mineral composition, every unit exhibits a single crystal behavior as previously shown by multiple $X$-ray diffractions (Figure 4 in [16]). In addition, every unit shows a different orientation from that of its neighbors (Figure 5 in [16]). This point is important because, after being incorporated into the shell growing edge, these calcite units are acting as substrates for crystallization of the prisms. The amorphous calcium carbonate simultaneously secreted by the mantle cells will crystallize by following the crystalline orientation of the underlying disks [18]. Note must be made that from this point, growth of the prisms is simultaneous $[16,19]$, whereas periostracal disks individually grow.

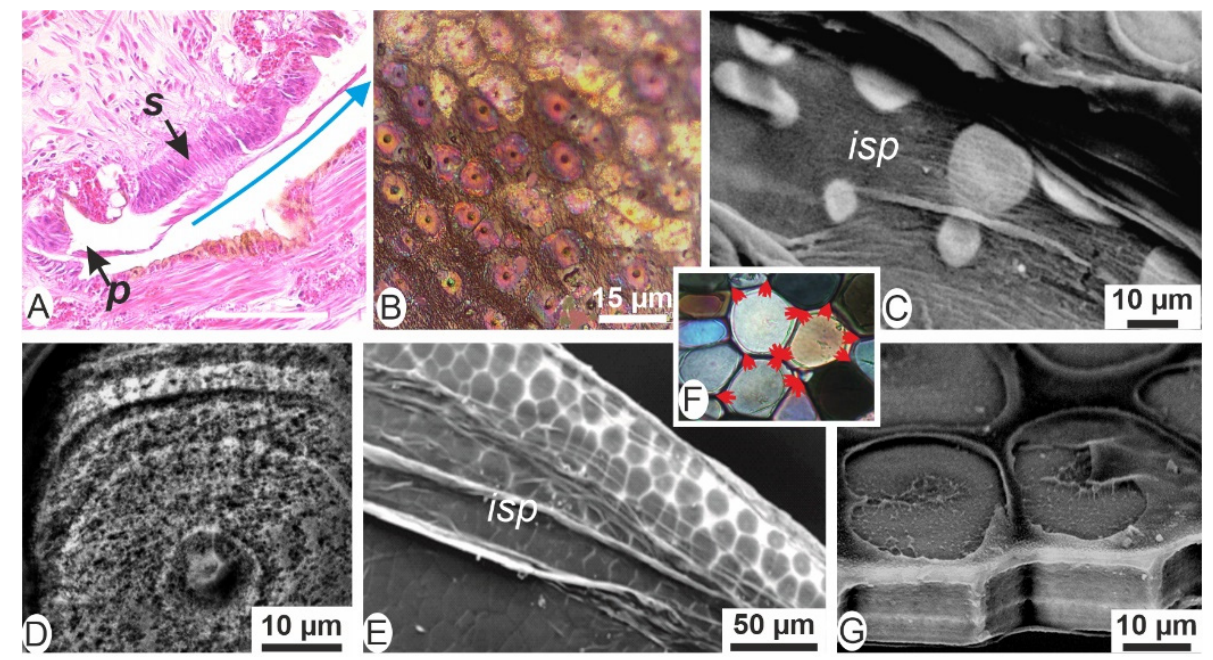

Figure 6. Role of the periostracum in the formation of the shell outer layer. (A) Histological view showing the origin of the periostracum $(p)$ in the deeper part of the outer mantle grove and the first secretion onto its inner surface (s) - Image credit: A. Fougerouse, DRM. Periostracum is continuously secreted (on a stepping mode) and it progresses towards the shell growth edge (blue arrow). (B) Statistical deposition of the organic centers surrounded by the earliest secondary deposition. (C) Mineralized disks whose diameters progressively increase. (D) Stepping mineralization of the disks forming concentric rings surrounding the initial center. (E) Disk reaching the shell growing edge visible through the internal side of the periostracum (isp). (F) Deposition of calcium carbonate by the mantle contributes to create the rigid shell. (G) Oblique view of the shell prisms showing their outer sides made by the partly decayed periostracum with the underlying disks and the first common growth steps of the shell. 
Compared with this well-organized stepping calcification process that obviously requires strong biological spatial and timing coordination, the contrast is striking with the branching growth mode of the early calcite deposition by the pearl sac (Figure 7D). Conclusively the earliest calcite deposition by the pearl sac onto the nucleus surface does not support the similarity with the complex process of calcite deposition in shell development.

\subsection{Origin of Crystalline Orientation in Shell Prisms Compared with Crystalline Consistency of Calcite Depositions in Pearls}

A major difference between the early secretions of the pearl sac onto the nucleus surface (Figure 7A-C) and the periostracum is also clearly appearing when considering crystalline orientations of the mineral components.

In the development of the shell growing edge, it has been shown that periostracum is acting only as a conveyor belt moving the calcite disks from the deeper part of the outer mantle grove up to the shell border [16]. Crystalline orientation of the calcite disks is given by the initial organic centers deposited onto the internal surface of the periostracum [18]. In contrast, the organic layer secreted by the pearl sac and progressively covering the nucleus (Figure 7A-C) has a leading role regarding crystalline orientation of the tiny mineral particles it is bearing. Evidence of some consistency in crystallographic orientation of these particles in the flushing mucus is suggested by observation in polarization microscopy of the surface of the branching crystallization (Figure 7D,E).

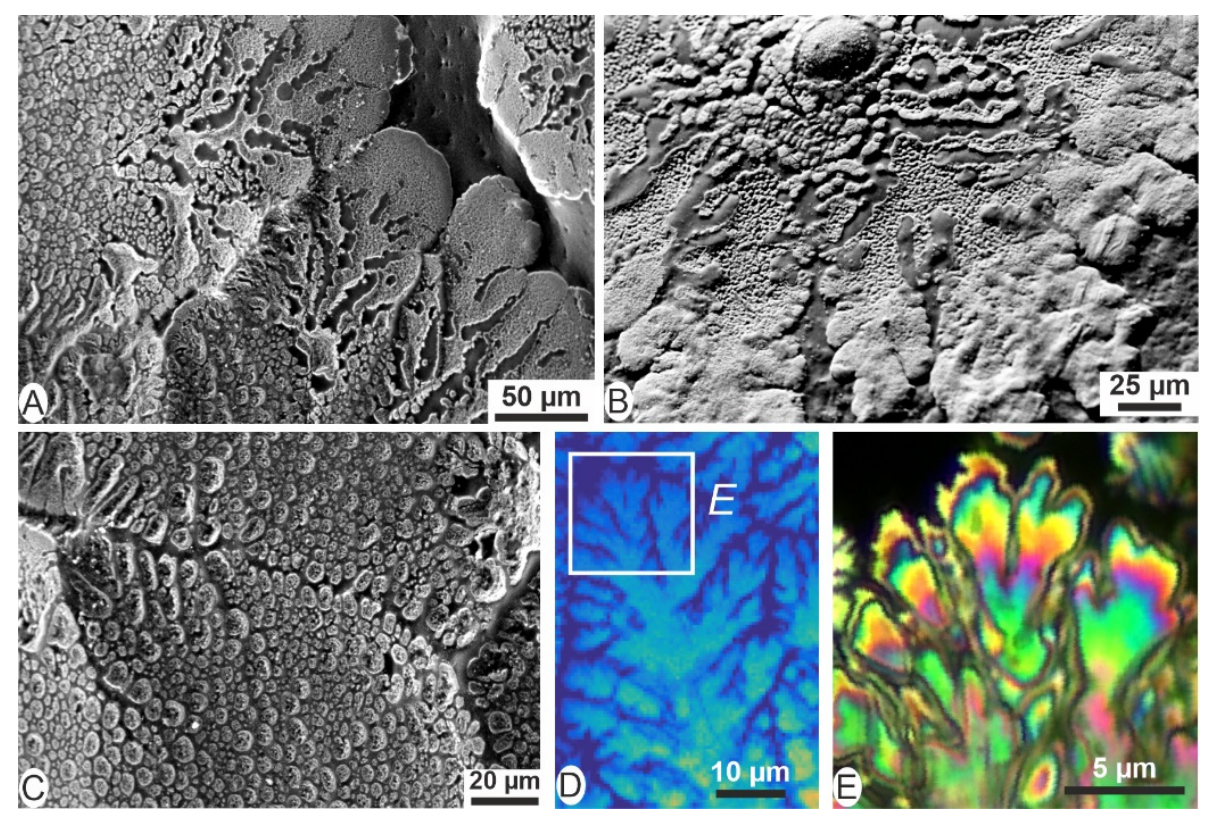

Figure 7. Expanding mucus onto the nucleus surface and its leading role in the first crystallization. $(\mathbf{A}, \mathbf{B})$ Earliest secretions by the pearl sac appear as expanding mucus radiating from centers. (C) The diverging branches comprise tiny particles forming the earliest mineral units. (D) Calcium fluorescence from the end of an expanding sector. (E) Polarized light optical microscopy of the end of this expanding sector provides evidence of the consistency in crystallographic arrangement of the mineral particles.

\subsection{Composition, Mineralogy: Diversity and Coexistence in Close Proximity}

A major obstacle to the rejuvenescence program postulated by the reversed shell theory is that calcite and aragonite in the early mineralization stages of pearl development crystallize in close proximity. In development of the shell of P. margaritifera, calcite, and aragonite are simultaneously produced in clearly separated areas (Figure 8E,F in [16]).

Whatever their shape, the early pearl layers are a mixture of organic and mineral components, as shown by the comparison of SEM images in secondary electron (SE) and backscattered mode (BSE) (Figure 8A,B). The grayish SE image shows a slight difference 
between the outer region and the middle of the branching deposits (Figure 8A), but the BSE clearly evidence the difference of the degree of mineralization between these two zones (Figure 8C). From these images, it seems that the beginning of a branching deposit is not rich in $\mathrm{Ca}$ and $\mathrm{Sr}$, indicative of calcium carbonate. Detailed images of the mineralized outer region reveal a nanogranular structure (Figure $8 \mathrm{C}$ ).

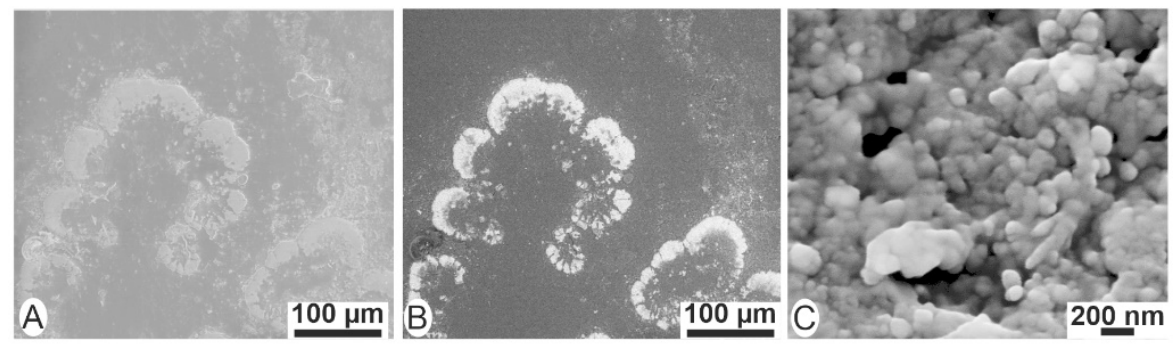

Figure 8. (A) SEM image in SE mode does not emphasize the heterogeneity of the branching deposit. (B) BSE mode clearly displays the contrast between mainly organic (black) and mainly mineralized (white) zones. (C) Nanogranular structure of the mineralized deposits.

FTIR spectra of the calcite and aragonite groups are characterized by three major bands attributed to the carbonate ion $\mathrm{CO}_{3}{ }^{2-}: \mathrm{v} 3$ at $1429 \mathrm{~cm}^{-1}$, the $v 2$ doublet $877-848 \mathrm{~cm}^{-1}$, and $v 4$ at $713 \mathrm{~cm}^{-1}$ for calcite; $v 3$ at $1471 \mathrm{~cm}^{-1}$ and two doublets $v 2$ at $858-844 \mathrm{~cm}^{-1}$ and $v 4$ at $713-700 \mathrm{~cm}^{-1}$ for aragonite $[20,21]$. The weak carbonate $v 1$ band is at $1012 \mathrm{~cm}^{-1}$ for calcite and at $1083 \mathrm{~cm}^{-1}$ for aragonite. The main peaks assigned to proteins are the amide I bands $\left(\sim 1650 \mathrm{~cm}^{-1}\right)$, amide II $\left(\sim 1550 \mathrm{~cm}^{-1}\right)$, and amide III band $\left(1310-1240 \mathrm{~cm}^{-1}\right)$. Bands between $1230 \mathrm{~cm}^{-1}$ and $1265 \mathrm{~cm}^{-1}$ are assigned to sulphate [22,23]. Bands between $1180 \mathrm{~cm}^{-1}$ and $1200 \mathrm{~cm}^{-1}$, and between $1370 \mathrm{~cm}^{-1}$ and $1420 \mathrm{~cm}^{-1}$ are due to organic sulphate, whereas inorganic sulphates are between $1080-1130 \mathrm{~cm}^{-1}$ [24].

Infrared spectra of the first pearl layers show that aragonite and calcite exist (Figure 9A). Adjacent irregular units are visible in calcite (Figure 9B), but not in aragonite (Figure 9C). The size of the analyzed region is $70 \mu \mathrm{m}$, so that the difference of structure between calcite and aragonite is visible (Figure 9D). Moreover, the coexistence and juxtaposition of both polymorphs are detected (Figure 9A). The spectrum shows the aragonite is rich in organic matrix and poorly crystalline. Calcitic deposits are rich sugars $\left(998 \mathrm{~cm}^{-1}\right.$ band $\left.[25,26]\right)$.

Two main categories of minerals are also revealed by $\mu$-XANES analysis at the $S$ K-edge (Figure 10). Sulfur in calcareous biominerals was identified on corals and mollusks [27]. $S$ is known in amino acids (cysteine, cystine, and methionine), and in sulphated acidic sugars. In calcitic mollusk shells, the content in organic sulphated sugars is higher than that of amino acids in the intraskeletal matrix. From the ratios of the surface of the two main peaks (2.472 for $S$ in amino acids, and 2.48 for sulphated sugars), two populations are differentiated (Figure 9). When compared with data resulting from other analyses, it can be suggested that the high ratios are present in aragonite units, whereas low ratios are those of the calcite units.

All these observations confirm the results of synchrotron X-ray fluorescence and Xray diffraction. Two categories of early deposits in the pearl layer are identified in the neighboring units: calcite and aragonite. These polymorphs are known in Pinctada shells, but here they are not regularly arranged and superimposed. Moreover, the nacreous tablets and the calcitic prisms are not visible.

These converging conclusions obtained from various methods lead to the opinion that the early secretions by the pearl sac cannot be assimilated to a rejuvenescence program that should be responsible for the formation of a 'reversed shell'. In contrast to such a new biomineralization program (that should lead to similarity between the pearls), the huge diversity in pearl morphology is due to variable alterations of the biomineralization mechanism following diversity in physical conditions during the grafting process. 


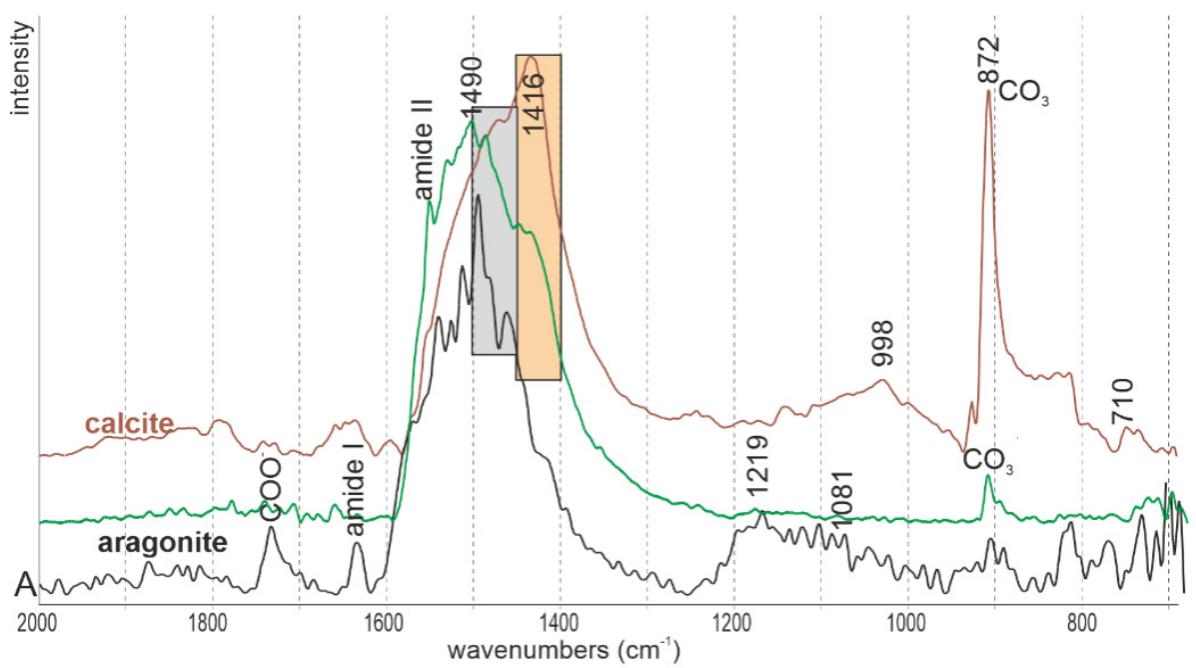

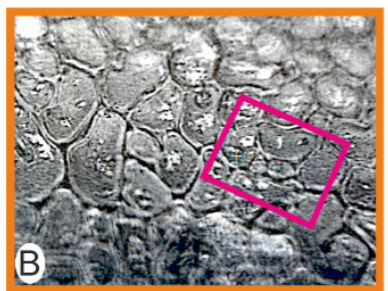

calcite

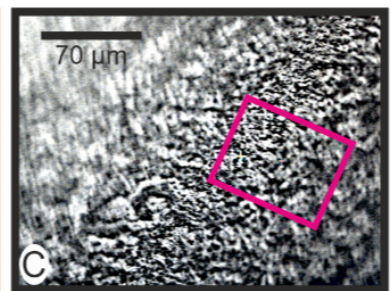

aragonite

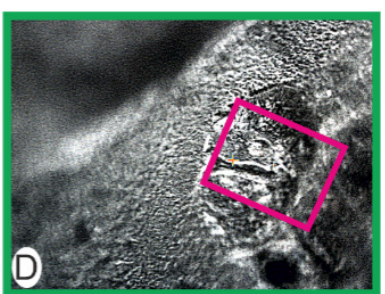

aragonite + calcite

Figure 9. FTIR spectra of first deposits: prismatic calcite $(\mathbf{A}, \mathbf{B})$, microgranular aragonite $(\mathbf{A}, \mathbf{C})$ and a mixed zone (A,D). Grey rectangle: range of $\vee 3$ band for aragonite; orange rectangle; range of $\vee 3$ band for calcite.

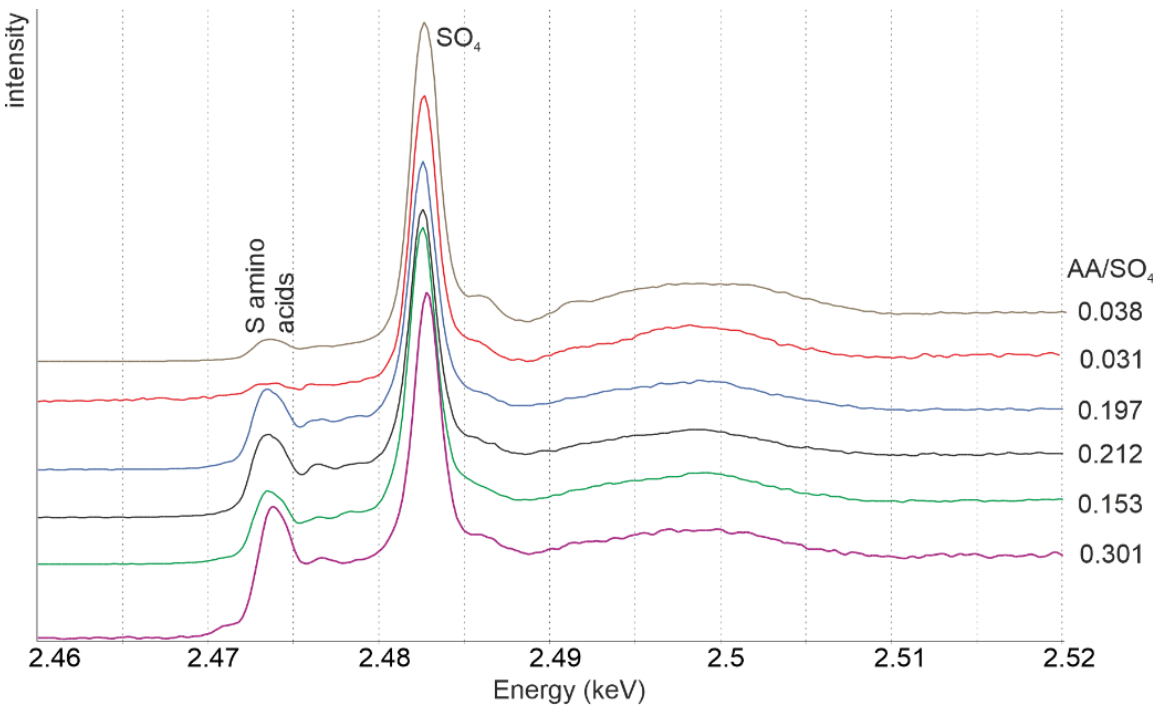

Figure 10. Micro-XANES spectra at the S K edge showing the presence of two categories of pearl layer deposits: one is rich in sulfur amino acids, another one poor in these amino acids.

4.4. Physical Patterns of the Earliest Mineral Deposition by the Pearl Sac Provide Evidence of Degradation in the Nacre Producing Mechanism

The reported results show that synchrotron-based fluorescence and X-ray mapping measurements allow for a precise comparison to be made between pristine nacreous structures in shells and early mineral depositions by the pearl sac. This might be a valuable approach to evaluate the biological changes that have obviously occurred in the mineralizing cells of the mantle during the grafting process. 
A series of investigations conducted with increasing spatial resolution has led to the conclusion that both prisms and nacre exhibit essentially similar ultrastructures at the nanometer range (Figure 11) [27]. Although their structures and mineralogy differ (Figure 11A,B,D,E), nacre and prisms are built by layers of organically coated mineral grains whose thickness is in the micrometer range (Figure $11 \mathrm{C}, \mathrm{F}$ ).

Note must be made that formation of these mineral layers is compatible with the current exocytosis model in which interactions between amorphous calcium carbonate (stored into the mineralizing cells) and the specific blends of organic compounds enable extracellular formation of the calcite and aragonite grains [28]. A recently isolated protein [29] exemplifies how such a mineralogical discrimination may occur from a common intracellular resource.

However, in the regular mineralization process of shell formation, the mineral grains are produced in distinct areas of the shell mantle (the outer one forming calcite and the inner one aragonite) and accordingly are subdivided into specifically shaped units by formation of the organic envelopes. This regular association between mineralogy and specific spatial arrangement of the envelope forming molecules results in the long recognized microstructure of the prismatic and nacreous shell layers. Conversely, genomic data obtained on grafted samples display irregular gene expressions. For a given pearl sac, expression of the mineralizing genes was obtained from the whole pearl-sac used as a single data source. Pearl sacs are different with respect to the expressions of the genes involved in mineralization (Supplementary File S2).

It is worth noting that such coordination between mineral grains and the organic envelopes is a stepping process investigated for both prisms and nacre in the P. margaritifera shell [11]. With particular interest regarding the grafting process, the distinct steps predating the final status of nacre have been established.

The reported results reveal a clear opposition between the behavior of the two main components of the shell (mineral grains and microstructural envelopes) submitted to grafting process.

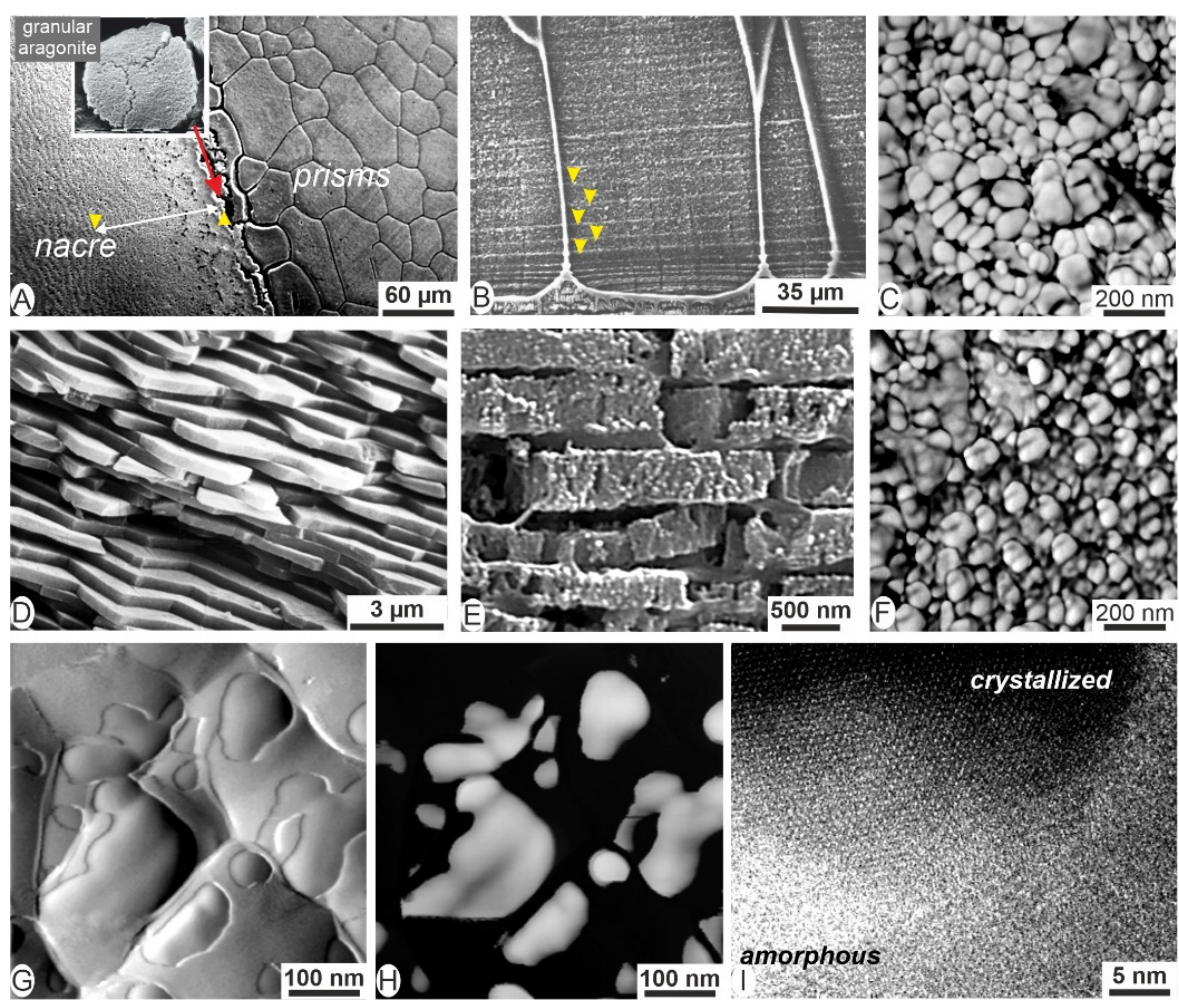

Figure 11. Similarity of ultrastructures in the calcite prisms and nacre of the P. margaritifera. (A) Inner side of a valve showing the transition area between the end of prismatic domain (right) and the first 
occurrence of nacreous area. The nacreous area begins by deposition of aragonite made of submicrometric grains. (B) SEM image showing the layered structure of prisms. (C) AFM phase contrast image showing the granular nanostructure of the prisms. (D-F) Ultrastructure of nacreous tablets also built by nanograins. (G) AFM amplitude image of the nanogranular structure of the prisms. (H) AFM phase image contrast of the same zone, showing black areas (organo-mineral contents) and the mainly mineral gray areas. (I) Crystallization of grain core surrounded by persistent amorphous material made visible in transmission electron microscopy.

In every reported example, the consistency of crystallographic orientation for the mineral grains has been established, contrasting with the absence of the microstructural envelopes. This transforms the mineral secretion mechanism into a free-running mineralization process, with no remaining indication of the specific micro-structural organization for both aragonite and calcite. From a biomineralization viewpoint, this suggests different sensitivities between grain and envelope formations regarding the operational stress caused by the grafting process.

Therefore, from a practical viewpoint, deciphering the structural alterations in the early mineralization by the pearl sac might be an efficient approach to evaluate the biological degradation of the biomineralization mechanism between pristine nacre produced by the graft as a part of the shell mantle and mineralization by pearl sac resulting from transportation of this graft into the host shell.

\section{Conclusions: Instead of a 'Reversed Shell' Growth Mode, a Post-Grafting Recovery Process May Help to Understand Early Calcifications in Pearl}

Results obtained by synchrotron-based characterizations of the earliest mineral depositions in the cultivated pearls clearly disprove their commonly admitted similarity with the periostracum of the Pinctada shells:

- Contrasting to the regular layering admitted by the "reversed shell" theory, the earliest post-grafting mineralizations are highly irregular from both structural and mineralogical view-points;

- In the development of the Pinctada shells the periostracum is acting only as the conveyor of the mineral structures that are produced by the epithelial cells of the outer mantel grove, whereas the first organic deposition in pearls creates the new mineral units;

- These earliest mineralizing secretions of the peal sac can produce calcite or aragonite units even within a given pearl sac: this never occurs in the Pinctada shells in which the periostracal disks and later the prisms of the outer layer are invariably made of calcite. Simultaneous deposition of calcite and aragonite never occurs at the shell growing edge.

These data clearly establish that the earliest pearl sac secretions cannot be considered equivalent to the shell periostracum. This conclusion takes place after previous studies that have shown the unlimited diversity of the early mineral depositions in pearls and their progressive return to nacre secretion.

Instead of a 'reversed shell' growth mode, the non-nacreous structures that occur below the nacreous layers of the cultivated pearls can be viewed as the result of a postgrafting recovery process after disturbance of the mineralization mechanism in the graft cells (and later the peal sac). Diversity of these earliest mineral deposits suggests that during the grafting process the genomes of the cells were submitted to variable alterations depending on the operational grafting conditions.

Supplementary Materials: The following supporting information can be downloaded at: https: / / www.mdpi.com/article/10.3390/min12020172/s1, File S1: Summary of the grafting process for pearl production [30]; File S2: Expression of gene activity [31]. 
Author Contributions: Conceptualization, J.-P.C.; software, K.M.; investigation, J.-P.C., Y.D., C.L., K.M., D.S., A.S.; resources, J.-P.C., Y.D., C.L., K.M., D.S., A.S.; writing-original draft preparation, J.-P.C., Y.D.; writing—review and editing, J.-P.C., Y.D.; funding acquisition, J.-P.C., Y.D. All authors have read and agreed to the published version of the manuscript.

Funding: This research was funded by the SOLEIL Grants201770784 and 20180995, and ESRF LS2563 to J.-P.C. and Y.D.

Institutional Review Board Statement: Not applicable.

Informed Consent Statement: Not applicable.

Data Availability Statement: The raw/processed data required to reproduce these findings cannot be shared at this time due to legal or ethical reasons.

Acknowledgments: Authors are grateful to M. Salomé (ID21 ESRF), for assistance with XANES acquisition. We thank the three anonymous reviewers for their helpful suggestions and positive comments.

Conflicts of Interest: The authors declare no conflict of interest. The funders had no role in the design of the study; in the collection, analyses, or interpretation of data; in the writing of the manuscript, or in the decision to publish the results.

\section{References}

1. Kawakami, I.K. Studies on pearl formation. On the regeneration and transformation of the mantle piece in the pearl oyster. Mem. Fac. Kyushu Univ. 1952, E1, 83-89.

2. Kawakami, I.K. Marine regeneration in pearl oyster (Pinctada martensii). J. Fuji Pearl. Inst. 1952, 2, 1-4.

3. Bøggild, O.B. The shell structure of mollusks. Kgl. Dan. Vidensk. Selbsk. Skrifter. Naturvidensk. Math. 1930, 9, $231-326$.

4. Taylor, J.D.; Kennedy, W.J.; Hall, A. The shell structure and mineralogy of the Bivalvia. Introduction, Nuculacea-Trigonacea. Bull. Br. Mus. (Nat. Hist.) Zool. Ser. 1969, 3 (Suppl. 3), S1-S124. [CrossRef]

5. Wada, K. Microscopic observations of cultured pearls at their early formation. Bull. Nat. Pearl Res. Lab. 1957, 3, 167-174.

6. Tsuji, T. Studies on the mechanisms of shell and pearl formation in Mollusca. J. Fac. Fish. Prefect. Univ. Mie 1960, 5, 1-70.

7. Dix, T.G. Histology of the mantle and pearl sac of the pearl oyster Pinctada maxima (Lamellibranchia). J. Malacol. Soc. Austr. 1973, 2,365-375. [CrossRef]

8. Taylor, J.; Strack, E. Pearl production. In The Pearl Oyster; Southgate, P.C., Lucas, J.S., Eds.; Elsevier: Amsterdam, The Netherlands, 2008; pp. 273-302.

9. Cuif, J.P.; Ball, A.D.; Dauphin, Y.; Farre, B.; Nouet, J.; Perez-Huerta, A.; Salomé, M.; Williams, C.T. Structural, mineralogical, and biochemical diversity in the lower part of the pearl layer of cultivated seawater pearls from Polynesia. Microsc. Microanal. 2008, 14, 405-417. [CrossRef]

10. Cuif, J.P.; Dauphin, Y.; Howard, L.; Nouet, J.; Rouzière, S.; Salomé, M. Is the pearl layer a reversed shell? A re-examination of the theory of pearl formation through physical characterizations of pearl and shell developmental stages in Pinctada margaritifera. Aquat. Liv. Res. 2011, 24, 411-424. [CrossRef]

11. Cuif, J.P.; Dauphin, Y.; Luquet, G.; Medjoubi, K.; Somogyi, A.; Perez-Huerta, A. Revisiting the organic template model through the microstructural study of shell development in Pinctada margaritifera, the polynesian pearl oyster. Minerals 2018, 8, 370. [CrossRef]

12. Dauphin, Y.; Belhadj, O.; Belllot-Gurlet, L.; Cotte, M.; Lo, C.; Medjoubi, K.; Somogyi, A.; Salomé, M.; Cuif, J.P. Inside black pearls. Mater. Charact. 2020, 163, 110276. [CrossRef]

13. Somogyi, A.; Medjoubi, K.; Baranton, G.; Le Roux, V.; Ribbens, M.; Polack, F.; Philippot, P.; Samama, J.P. Optical design and multi-length-scale scanning spectromicroscopy possibilities at the Nanoscopium beamline of Synchrotron SOLEIL. J. Synchr. Rad. 2015, 22, 1118-1129. [CrossRef] [PubMed]

14. Medjoubi, K.; Leclercq, N.; Langlois, F.; Buteau, A.; Lé, S.; Poirier, S.; Mercere, P.; Kewish, C.M.; Somogyi, A. Development of fast parallel multi-technique scanning X-ray imaging at Synchrotron Soleil. J. Phys. Conf. Ser. 2013, 463, 012031. [CrossRef]

15. Perez-Huerta, A.; Cuif, J.P.; Dauphin, Y.; Cusack, M. Crystallography of calcite in pearls. Eur. J. Mineral. 2014, 26, 507-516. [CrossRef]

16. Cuif, J.P.; Burghammer, M.; Chamard, V.; Dauphin, Y.; Godard, P.; Le Moullac, G.; Nehrke, G.; Perez-Huerta, A. Evidence of a biological control over origin, growth and end of the calcite prisms in the shells of Pinctada margaritifera (Pelecypod, Pterioidea). Minerals 2014, 4, 815-834. [CrossRef]

17. Checa, A.G. Physical and biological determinants of the fabrication of molluscan shell microstructures. Front. Mar. Sci. 2018, 5, 353. [CrossRef]

18. Cuif, J.P.; Dauphin, Y. The Marsh's membrane: A key-role for a forgotten structure. In Biomineralization, from Molecular and Nano-Structural Analyses to Environmental Science; Endo, K., Kogure, T., Nagasawa, H., Eds.; Springer: Berlin. Germany, 2018; pp. 349-357. 
19. Checa, A.G.; Bonarski, J.T.; Willinger, M.G.; Faryna, M.; Berent, K.; Kania, B.; Gonzalez-Segura, A.; Pina, C.M.; Pospiech, J.; Morawiec, A. Crystallographic orientation inhomogeneity and crystal splitting in biogenic calcite. J. R. Soc. Interface 2013, 10, 20130425. [CrossRef] [PubMed]

20. Adler, H.H.; Kerr, P.F. Infrared absorption frequency trends for anhydrous normal carbonates. Am. Mineral. 1963, 48, 839-853.

21. Jones, G.C.; Jackson, B. Infrared Transmission Spectra of Carbonate Minerals; Springer Science: Berlin, Germany, 1993; 233p.

22. Cael, J.J.; Isaac, D.H.; Blackwell, J.; Koenig, J.L. Polarized infrared spectra of crystalline glycoaminoglycans. Carbohydr. Res. 1976, 50, 169-179. [CrossRef]

23. Cabassi, F.; Casu, D.; Perlin, A.S. Infrared absorption and Raman scattering of sulfate groups of heparin and related glycosaminoglycans in aqueous solutions. Carbohydr. Res. 1978, 63, 1-11. [CrossRef]

24. Coates, J. Interpretation of infrared spectra, a practical approach. In Encyclopedia of Analytical Chemistry; Meyers, R.A., Ed.; John Wiley \& Sons Ltd.: Chichester, UK, 2000; pp. 1-23.

25. Ferrier, R.J. Other physical methods. In Carbohydrate Chemistry; The Royal Society of Chemistry: London, UK, 1998; Volume 30, pp. 329-349.

26. Cadet, F.; Offmann, B. Extraction of characteristic bands of sugars by multidimensional analysis of their infrared spectra. Appl. Spectrosc. 1997, 51, 369-375. [CrossRef]

27. Cuif, J.P.; Dauphin, Y.; Sorauf, J.E. Biominerals and Fossils through Time; Cambridge University Press: Cambrigde, UK, 2011; 490p

28. Beniash, E.; Aizenberg, J.; Addadi, L.; Weiner, S. Amorphous calcium carbonate transforms into calcite during sea urchin larval spicule growth. Proc. R. Soc. Lond. 1997, B264, 461-465. [CrossRef]

29. Kong, J.; Lio, C.; Yang, D.; Yan, Y.; Chen, Y.; Huang, J.; Liu, Y.; Zhang, G.; Xie, L.; Zhang, R. Alv protein plays opposite roles in the transition of amorphous calcium carbonate top calcite and aragonite during shell formation. Cryst. Growth Des. 2018, 18, 3794-3804. [CrossRef]

30. Soldati, A.L.; Jacob, D.E.; Wehrmeister, U.; Hofmeister, W. Structural characterization and chemical composition of aragonite and vaterite in freshwater cultured pearls. Mineral. Mag. 2008, 72, 577-590. [CrossRef]

31. Marie, B.; Joubert, C.; Tayalé, A.; Zanella-Cléon, I.; Belliard, C.; Piquemal, D.; Cochennec-Laureau, N.; Marin, F.; Gueguen, Y.; Montagnani, C. Different secretory repertoires control the biomineralization processes of prism and nacre deposition of the pearl oyster shell. Proc. Natl. Acad. Sci. USA 2012, 109, 20986-20991. [CrossRef] [PubMed] 